\title{
Autism Spectrum Disorder: Experiences of Mothers Before and After Their Children's Diagnosis and Implications for Early Special Education Services
}

\author{
İlknur Çifci Tekinarslan \\ Correspondence: İlknur Çifci Tekinarslan, Faculty of Education, No: Z-20, Bolu Abant Izzet Baysal University, Gölköy \\ Campus, 14030 Bolu, Turkey.
}

Received: August 19, 2018

doi:10.11114/jets.v6i12.3692
Accepted: October 8, $2018 \quad$ Online Published: October 16, 2018

URL: https://doi.org/10.11114/jets.v6i12.3692

\begin{abstract}
Mothers of children diagnosed with Autism Spectrum Disorder (ASD) face various burdensome challenges in many stages of their lives. This study aimed to explore the experiences of Turkish mothers whose children were diagnosed with ASD in terms of the emotions they felt and the challenges they encountered before and after the diagnosis. 17 mothers participated in this study which was designed in line with qualitative research methods and participant information form based on demographic characteristics was utilized to collect data along with the interview form composed of 11 questions. Findings from face-to-face interviews conducted with mothers showed that mothers thought their children had some problems as a result of their observations of limitations in communication skills, limitations in social interactions and some problem behaviors in their children. Children were diagnosed with ASD by doctors during the preschool period. Mothers expressed that they had experienced grief, denial, anxiety and fear after the diagnosis and stated that these feelings had not changed. In addition, mothers mentioned that they had changes in their family lives and that they maintained a child-centered life. Mothers pointed out that they generally spent their time doing research and gathering information on the subject. Research findings reveal the necessity of taking these mothers' experiences into account in early special education services and the need for planning these services to meet these mothers' needs.
\end{abstract}

Keywords: Autism Spectrum Disorder, mother's views, early education services

\section{Introduction}

Having a disabled child has a significant impact on family life and parents try to adapt to their new roles and responsibilities (Hallahan \& Kaufman, 2009). Physically and psychologically, mothers spend their time and energy for the daily care of their disabled children. Loss of the expected "normal" child and acceptance of a "disabled" child instead is not easy. It is a very hard process to for the disabled child to be integrated into the family and be accepted by family members and in the meantime continuing normal family life with a member who is different (Sari, Baser \& Turan, 2006). Mothers are more affected by this strenuous process, have difficulty in understanding their children's diagnosis, and are exposed to intense stress (Lai \& Mackenzie, 2002; Kerr \& Mcintosh, 2000). The previous studies concluded that stress levels of parents with children with disabilities are higher than those of parents with children with normal developmental patterns (Roach \& Orsmand, 1999; Ong, Chandran, \& Peng, 2005). This stress is more intense in parents who have a child with Autism Spectrum Disorder (ASD). ASD is a specific neuropsychiatric disorder that begins in the early stages of life and lasts for life; it is defined by delays and deviations in social relations, communication, behaviors and cognitive development (Davison \& Neale, 2004).

Problems of children with ASD in communication and social skills, and problem behaviors that they experience, especially sleeping problems, cause their parents to have various challenges. This leads to a life of chronic sadness and depression for parents, leading to negative attitudes and self-accusation rather than a positive approach to life (Desai, Divan, Wertz, \& Patel, 2012).

Literature presents various studies to investigate what parents experience after learning their child's diagnosis of "disability" and to determine how parental reactions vary in different cultures. In this context; Lai and Mackenzie (2002) studied the experiences of mothers with children who have Down syndrome from Hong Kong, Ong, Chandran and Peng (2005) explored Malaysian mothers with children with mental retardation, Desai et al. (2012) investigated Indian mothers of children with ASD and McCabe (2008) reported the experiences of Chinese mothers of children with ASD. Kermanshahi, Vanaki, Ahmedi, Kazemnejad and Azadfalah (2008) investigated the experiences of Iranian mothers who 
have children with learning disabilities. These studies emphasize the stressful lives of mothers and the importance of providing information to mothers in regards to their children. Noting the fact that parental reactions are well documented in the Western culture but they are not investigated in different cultures; Huang, Kellett and St. John (2010) studied the responses of parents towards their disabled children in Taiwan, a country influenced by Confucianism. The researchers conducted semi-structured interviews with 15 mothers of children with cerebral palsy (CP). It was determined that these mothers had a sense of lack of control in their lives, felt incapacitated and experienced feelings of mistrust for health care personnel. It was also identified that learning about their children's diagnosis caused a crisis in the family which experienced shock, denial of the diagnosis, fury and fear. Mothers of children with CP reported that they lost their "ideal" children after their children's diagnosis along with their expectations for "normal" motherhood and fulfilling the social expectations to give birth to healthy children. These mothers expressed mixed feelings, faithlessness, rejection, self-blame and grief, combined with the uncertainty about the future of their child. Study results included recommendations to provide the mother and the family with emotional support and information both during diagnosis and in the period after diagnosis in order to ensure a better understanding of the child's situation.

The investigations carried out in Turkey include Cavkaytar, Batu and Çetin's (2008) study that explored the perceptions of Turkish mothers of children with developmental retardation. Data for this study were collected from 39 mothers by means of a semi-structured interview. It was determined that participating mothers experienced intense challenges in their daily lives with the birth of their children. In their study on the parental experiences of parents with disabled children after their children were diagnosed, Ciğerli, Topsever, Filiz-Alvur, and Görpelioğlu (2014) conducted semi-structured interviews with 37 mothers and 13 fathers and concluded that parents believed they were not sufficiently informed during diagnosis and experts did not adequately tended to their children. Parents reported that they needed psychological support after the diagnosis and that there were differences between the spouses in regards to the care of child care which were reflected on their relationship. In a study that examined the experiences of twenty mothers of children with ASD, Güleç-Aslan, Cihan and Altın (2014) asked the question "What is ASD like?" and descriptively analyzed the obtained metaphors. Results demonstrated that mothers perceived ASD as a pervasive condition that negatively affects and encompasses all aspects of their lives. Selimoğlu, Özdemir, Töret and Özkubat (2014) conducted interviews with 50 parents who were the primary caregivers of children with ASD ranging in age from 2 to 12 years in order to determine their views on their experiences during diagnosis, their education and available health resources and their needs. Mothers stated that there were limitations in assessments during the diagnosis process, inadequacies in support services to be provided in accordance with parental needs and that problems in special education services offered to children.

Studies in the literature explored parental reactions with the help of data obtained from study groups with the participation of both mothers and fathers and they included parents of children with mental retardation, Down syndrome, ASD and CP. However, studies on Turkish mothers of children with ASD are limited (Bıçak, 2009; Bilgin \& Küçük, 2010; Selimoğlu et al., 2014; Üstüner-Top, 2009).

Early educational services are crucial in special education. Offering early education services immediately after diagnosis is essential both for parents and for the development of children with ASD. Ecological Systems Theory (Bronfenbrenner, 1979), Transactional Model of Development (Sameroff \& Fiese, 2000) and Family Systems Theory (Wehman, 1998) regard the family as the most important factor in the development of the child and indicate that a situation that affects a member of the family affects other members of the family as well. Early educational services developed on the basis of these theories aim to positively change parental emotional reactions towards their children to the degree parents integrate the implemented early education programs in their lives. Like all children, children with ASD learn their skills from their parents, especially from their mothers.

The current study aimed to explore the experiences of Turkish mothers whose children were diagnosed with ASD in terms of the emotions they felt and the challenges they encountered before and after the diagnosis. In addition, based on the findings that are thought to be guiding in the field, implications and recommendations are provided for the planning and implementation of early special education services for mothers to ensure the highest level of benefit from these services. The study specifically sought answers to the following questions:

1. What kind of experiences do mothers of children with ASD have in terms of emotions they felt and challenges they encountered before and after diagnosis?

2. Based on these findings, what kind of implications or recommendations can be made for special education services aimed at mothers of children with ASD? 


\section{Method}

\subsection{Research Design}

This study, conducted to determine the pre and post diagnosis experiences of mothers of children with ASD, made use of phenomenology research method which is one of the qualitative research methods. Qualitative phenomenological research aims to present the perceptions and experiences of individuals towards a phenomenon and the meanings they ascribe to these perceptions and experiences (Yıldırım \& Şimşek, 2008). With this method, it will be possible to describe the emotions and experiences of mothers of children with ASD.

\subsection{Data Collection Technique}

This phenomenological study utilized semi-structured face-to-face interview technique to collect data. Face-to-face interviews are types of conversations conducted with the intent of obtaining an individual's opinion. Interview technique is categorized under three headings: unstructured interviews, semi-structured interviews and structured interviews. In semi-structured face-to-face interviews, included in this classification, the interviewer prepares the questions in advance before the interview and directs the questions to the interviewee (Yıldırım \& Şimşek, 2008). The interviewer in this study also utilized additional questions besides the pre-determined semi-structured questions on the interview form when more detailed answers were required during the interview.

\subsection{Data Collection Tools}

Literature review was conducted to prepare the face-to-face interview form composed of 11 semi-structured questions directed at mothers. After consulting two field experts, some modifications were done in the form. In addition to the questions on the interview form, participant information form was prepared to collect mothers' demographic information. Opinions of an expert were sought before the participant information form was finalized. Following this process that ensured content validity, a pilot implementation was organized to check functionality of the questions and an interview was conducted with one mother to obtain information on the intelligibility of interview questions. Pilot application ensured that questions were comprehensible, the participating mother could easily answer the questions and it was possible to gather the appropriate data. Table 1 presents the 11 questions asked in the interview.

Table 1. Interview questions

1. When did you first think that your child was different and something was wrong? And how did you realize your child was different from other children?

2. How, when, where and by whom were you told about your child's disorder?

3. What did you feel and how did you react when you learned about your child's diagnosis?

4. How did your husband, your other children and your parents react to your child's diagnosis?

5. What has changed in your family life after you learned about your child's disorder?

6. What feelings did you experience while you were raising your child?

7. What has changed in your feelings/emotions since you learned about your child's diagnosis?

8. After all your experiences and the years that you left behind, would you feel the same if you could go back to the first moment you learned that you would have a special child? Would your reactions change?

9. What has been the most upsetting thing for you since you learned about your child's diagnosis?

10. With who have you shared the feelings you have experienced since you learned about your child's diagnosis? How did these people react?

11. What challenges do you think you will face in regards to your child's future?

\subsection{Participants}

Study participants were selected by criterion sampling method, which is one of the purposeful sampling methods (Yildırım \& Şimşek, 2008). In line with this sampling method, some criteria were taken into consideration in the selection of the participating mothers such as voluntary participation in the research and being the birth mother of a child diagnosed with ASD. Table 2 summarizes the characteristics of mothers who voluntarily participated in the study. As seen in Table 2, a total of 17 mothers participated in the study. Characteristics of mothers show that mothers' ages were in the range of 24-38; they represented a wide spectrum in educational status ranging from primary school to master's degree and except for three, the participating mothers did not work outside the home and were housewives. Participating mothers' children with ASD ranged between 3 to 8 years old and they all had medical diagnosis by doctors. The children were diagnosed with ASD during the preschool period and their ages ranged between 1.5 and 3 years when they were diagnosed. All children of mothers who participated in the study were boy, because the prevalence rates of autism were more common among boys than girls (Halladay et al., 2015). 
Table 2. Information and numeric data on mothers' and child's characteristics

\begin{tabular}{|c|c|c|c|c|c|c|c|c|}
\hline 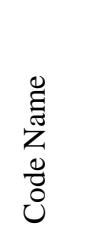 & $\underset{\pi}{\infty}$ & 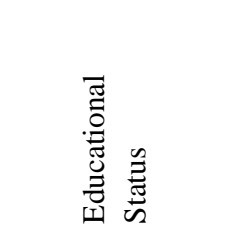 & 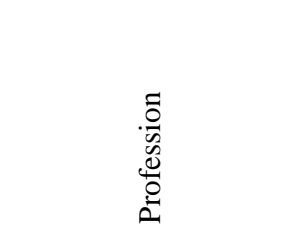 & 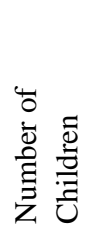 & $\begin{array}{l}0 \\
\sum_{1}^{\infty} \\
\infty \\
0 \\
00 \\
0 \\
0\end{array}$ & 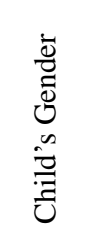 & 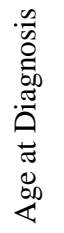 & $\begin{array}{l}\overline{8} \\
\frac{0}{0} \\
\tilde{v}\end{array}$ \\
\hline M1 & 30 & Associate degree & Caregiver in preschool & 1 & 4,5 & Male & 2 & Preschool \\
\hline M 2 & 35 & High school & Housewife & 2 & 3,5 & Male & 1,5 & Preschool \\
\hline M 3 & 27 & Master's degree & Housewife & 2 & 4 & Male & 3 & Preschool \\
\hline M 4 & 30 & High school & Housewife & 2 & 6 & Male & 3 & Preschool \\
\hline M 5 & 37 & University & Construction engineer & 2 & 6 & Male & 2 & Preschool \\
\hline M 6 & 27 & High school & Housewife & 1 & 4,5 & Male & 1,5 & Preschool \\
\hline M 7 & 24 & Secondary school & Housewife & 1 & 4,5 & Male & 2 & Preschool \\
\hline M 8 & 33 & High school & Housewife & 2 & 8 & Male & 2 & Elementary \\
\hline M 9 & 38 & Primary school & Housewife & 1 & 4 & Male & 2 & Preschool \\
\hline M 10 & 34 & Primary school & Housewife & 3 & 6 & Male & 2,5 & Preschool \\
\hline M 11 & 32 & High school & Housewife & 1 & 4 & Male & 3 & Preschool \\
\hline M 12 & 27 & High school & Housewife & 2 & 3,5 & Male & 3 & Preschool \\
\hline M 13 & 26 & Associate degree & Housewife & 2 & 4,5 & Male & 3 & Preschool \\
\hline M 14 & 27 & High school & Housewife & 2 & 4 & Male & 2,5 & Preschool \\
\hline M 15 & 30 & High school & Housewife & 1 & 3 & Male & 2,5 & Preschool \\
\hline M 16 & 29 & Primary school & Housewife & 2 & 5 & Male & 2,5 & Preschool \\
\hline M 17 & 37 & High school & Self-employed & 1 & 4 & Male & 2,5 & Preschool \\
\hline
\end{tabular}

\subsection{Data Collection Process}

The face-to-face interviews required by the qualitative data process were carried out at times and places appropriate for mothers. The interviews conducted with mothers were held at mothers' homes and at a suitable room located at the special education and rehabilitation centers where their children attended. Audio recordings were made for each interview. During interviews, mothers were provided with information about the purpose of the study and they were asked to express their views freely. The interview questions followed a specific framework and questions were repeated and required explanations were made when questions were not clear enough for the participants. Each interview lasted between 30 to 60 minutes.

\subsection{Data Analysis}

Data analysis was conducted following the steps provided below.

\subsubsection{Data Transcripts}

Following the completion of the interviews, transcripts of all the dialogues between the interviewer and participating mothers were digitally recorded on the computer without any editing or modification. Page numbers and lines were assigned for each transcript and 45 pages of transcripts were obtained in total. Arithmetic averages of interviews were taken and an expert listened to the first 10 and last 10 minutes of the audio recordings to check the accuracy of dialogue transcripts. During this process, the expert provided suggestions in regards to unintelligibility of some words and the need to exchange some of the words with others in the sentence structure. Hence, transcripts were reviewed as necessary.

\subsubsection{Preparations Before the Analysis}

Interviews were transferred to detailed interview forms composed of context information, descriptive data, descriptive index, index interpretation and page interpretation sections. Context information section included descriptive information such as the name /code name of the interviewed mother, date and location of the interview. Descriptive data section included the answers given by the mothers to the interview questions. Descriptive index section summarized mothers' answers by shortening them for easy comprehension. Index interpretation section included researcher's own interpretation of the interview data. Page interpretation included researcher's comments on the page. After the 
researcher completed these five sections for all interview transcripts, the reliability study was undertaken.

In order to check the reliability of the study, a field expert was provided with the first 10 and last 10 pages of the interview transcripts and requested to fill in the descriptive index, index interpretation and page interpretation sections. The forms filled by the researcher and field expert were compared, the descriptive index was discussed and an agreement was reached.

\subsubsection{Data Analysis Process}

Study data were analyzed by inductive analysis method. In this method, similar data are combined and rearranged based on specific concepts and themes in order to provide readers with ease in reading and comprehending the data. Inductive analysis is the process of making certain encodings and generating themes from these codes. Generating themes is the process of obtaining specific themes as a result of reviewing and associating the concepts obtained as a result of content analysis. The generated codes and themes help explain underlying theories (Yıldırım \& Şimşek, 2008).

\subsubsection{Generating Categories and Codes}

Transcripts were given page numbers. The data consisted of 45 pages and 1771 lines. The answers given by mothers were read several times and categories were coded by using letters. Interview questions were taken into account when the categories were generated. For instance, the first question "When did you first think that your child was different and something was wrong? And how did you realize your child was different from other children?" was categorized as "Initial awareness of the disorder and diagnosis" (IA).

\subsubsection{Filing the Encoded Data}

After data were coded, separate files were created for each code and relevant data were removed to appropriate code files. In this process, a colleague was asked to generate codes and categories contained in the code file independently. Thus, validity and reliability of data were obtained.

\subsubsection{Generation of Themes}

Codes were reviewed one by one and themes were generated as the next step after coding and categorization phase. Another expert was asked to revisit the themes which were finalized by comparing them with the themes obtained by the researcher.

\subsubsection{Validity and Reliability}

The first step for validity and reliability was taken by obtaining expert opinion for the interview questions prepared at the beginning of the study. Expert opinions were obtained for the participant information form as well. Voice recordings were reviewed by a specialist. An expert was asked to generate codes independent of the researcher. Also, expert support was received in generating themes and sub themes. Utmost care was taken to comply with ethical rules throughout the study and data records were not shared with anyone.

\section{Results}

Six themes emerged based on the interviews conducted with mothers of children with ASD as shown in Table 3. These themes are; first awareness of the disorder and diagnosis, emotional reactions (mother, father and other siblings), changes in family life, unsettling situations, thoughts for the future and source of emotional support. Mothers who were interviewed were coded with numbers ranging from 1 to 17 and they were quoted by citing their code numbers in relevant lines and pages of the transcripts. For instance, the second mother who was interviewed was coded as "M2" and the direct quote from this mother was provided in italics with the line and page number from interview transcripts.

\subsection{First Awareness of the Disorder and Diagnosis}

The first theme that emerged from the interviews with mothers of children with ASD $(n=17)$ was called "first awareness of the disorder and diagnosis". Mothers first became aware of their children's disorders as a result of observing their limitations in communication skills, limitations in social interactions and some problem behaviors. Findings relevant to this theme are provided below in sub headings:

\subsubsection{Limitations in Communication Skills}

Seven of the participating mothers (41\%) reported being initially aware of their children's situations as a result of their incompetence in communication skills. Some prominent examples for mother views in this regard are provided:

\footnotetext{
"I understood it from his lack of speech when my child was at the age of 1.5, he was not talking at all" (M6, p.2, l.74).

"We noticed it when he was at the age of 1.5. The child was only interested in one thing: playing with the car; never responded when I called him by name, he did not ask for anything, not even water, which I had to offer" (M4, p.1, ll. 38-40).

"We became motivated to do research based on reasons such as lack of eye contact, inability to look when he was
} 
addressed and inability to respond when we called him by name although he came running when the nylon bags gave a squeak" (M1, p.1, ll. 6-15).

"After about when he was 1.5. I understood it when he stopped talking and responding although he used to these before. So I understood it after he was 1.5 years old. He was completely unresponsive, never responded to my stimuli" (M2, p.1, ll. 33-35).

"We had doubts because the child was not talking and we took him to the doctor" (M3, p.2, l. 91).

Table 3. Codes and Themes

\begin{tabular}{ll}
\hline Theme Code & Themes \\
\hline IA & Initial awareness of the disorder and diagnosis \\
ER & Emotional reactions \\
CF & Changes in family life \\
UC & Unsettling situations \\
TF & Thoughts for the future \\
SS & Source of emotional support \\
\hline
\end{tabular}

\subsubsection{Limitations in Social Interactions}

Seven mothers (41\%) stated that they recognized limitations or problems in their children's social interaction skills. Here are some examples of mothers' opinions in this regard:

"Our child did not call us mommy-daddy, he did not adapt to us, I became suspicious when he was not able to adapt to people. The child marched to his own drum” (M10, p.2, ll. 80-81).

"Our child has never played with friends, he was always on his own, and then we took him to the doctor to understood what was going on" (M11, p.2, l. 84).

"The child did not look at us when we addressed him, he did not have much reaction to instructions. He was on his own, he was constantly locked in the TV. We noticed because of these behaviors" (M15, s.3, ll. 95-97).

\subsubsection{Problem Behaviors}

One of the mothers $(6 \%)$ stated that she understood something was different in her child as a result of his problem behaviors. This mother's view in this regard is as follows:

"When he was a baby, he was already not sleeping at all, never slept for 18 months, other than napping for 10 minutes then another 10 minutes. When I took him to the park, I used to put him in the stroller; other babies I met in the park would sleep in their strollers motionless, without moving at all. My baby was on the move constantly" (M6, p.2, ll. 56-67).

"And also, I understood later (that he was different) when his behavior became different than those of other children. I understood it because he was aggressive, very active, was not able to communicate with other children and was not able to socialize" (M6, p.2, ll.74-76).

\subsubsection{Diagnosis}

Mothers of children with ASD $(\mathrm{n}=17)$ were asked in the interview "How, when, where and by whom were they told about their child's disorder?". The responses provided by mothers to this question were divided into three categories: Age, location of diagnosis and the person who informed them.

\subsubsection{The Person Who Informed the Mothers}

Mothers of children with ASD reported that in addition to their own observations, they were first told about their children's developmental disorder by the senior members of their families (such as their own parents or their spouses' parents) or relatives (23\%) and doctors (76\%). Here are some of the prominent mother views on this subject:

"Relatives talked about it, they asked me why this child was like that; they told me he did not answer to his name, did not ask to give or be given anything, that he was behind his peers. After they talked to me, we started to observe more intensely. You know; otherwise you can never believe anything is wrong with your child. So; it happened this way” (M4, p.3, ll. 155-156).

"My mother realized it because of her previous experience with children, she warned us that he was supposed to do certain things in certain months, so we took him to a doctor" (M15, p. 7, ll. 255-258). 
"My mom and dad told me some things, but at first I did not believe it; later, in a hospital in Ankara, they (doctors) said it was autism. In fact, at that time, I even said it was only autism, not that important, etc. I later did some research, read some books, surfed the net since I did not know what autism was. I understood the situation later" (M1, p.3, ll.115-117).

\subsubsection{Location of Diagnosis}

All the mothers $(\mathrm{n}=17,100 \%)$ who answered the question regarding the place where their children were diagnosed with ASD answered that they were diagnosed at the hospital in the psychiatric clinic.

\subsubsection{Age}

According to the answers provided to the question regarding the age when their children were diagnosed, all participating mothers $\quad(n=15,88 \%)$ except two stated that their children were diagnosed with ASD in the age range of 2-3 which is the most common age range for ASD diagnosis. The remaining two mothers (12\%) stated that their children were diagnosed in an earlier age range of 1.5-2, when they went to a doctor due to some other health problems. One mother expressed her opinion as follows:

"He was not able to speak at two and a half years, the doctor said he would keep him under treatment and if that did not work out, we would apply for special education, we would get a report or something"(M16, p.7, ll. 273-274).deenmediklerini, altı anneninrum

\subsection{Emotional Reactions}

\subsubsection{Mothers' Emotional Reactions}

During the interviews held with mothers of children with ASD; eight (47\%) of the mothers stated that they experienced grief after the diagnosis and cried constantly. While seven mothers $(41 \%)$ reported denial and refusal about the diagnosis, one mother $(6 \%)$ said she experienced anxiety and fear. Some of the prominent views are provided below:

"I felt that my child's life was over; we were sad of course, we cried" (M1, p.8, ll.285-287).

"The shock I experienced lasted for a few days and how can I put it?... I was now constantly watching the child at home. I was constantly calling his name, I was constantly observing his reactions, I started to observe his facial expressions, everything" (M8, p.8, ll. 310-312).

"I was sad. He was behind his peers; he could not speak, so he was agitated because his friends used to exclude him because he could not speak. I felt grief, I cried" (M16, p.11, ll. 409-411).

\subsubsection{Fathers' Emotional Reactions}

During the interviews held with mothers, ten mothers (59\%) reported that their spouses did not accept their children's diagnosis with ASD, six mothers (35\%) stated that their spouses experienced grief and one mother (6\%) reported that her husband's emotional response was acceptance. Some of the mothers who reported their husbands were in denial expressed their views as follows:

"My husband did not accept it at first; he became a very different person, he became very frustrated" (M1, p.11, ll. 425-426).

"My husband did not come to terms with it for a very long time, could not accept it because he did not spend much time with the child" (M2, p. 12, ll. 472-473).

"At first, my husband did not want to believe it; he said our child would speak. In fact, he did not want to accept it because of his mother and father's pressure. He said our child would speak" (M16, p.15, ll.566-567).

3.2.3 Other Family Members' Emotional Reactions

When asked about the reactions of other family members (maternal grandmother, grandmother, paternal grandmother, etc.), to their children's diagnosis with ASD, eight mothers (47\%) stated that other family members did not accept the diagnosis, four mothers (24\%) reported that other family members experienced sadness and five mothers $(30 \%)$ identified that other members of the family blamed them as the mother and father. Some of the prominent examples of this heading are:

"Relatives said there was no such thing. They used to tell us that he was a very smart kid, very social, what the doctor told us was wrong, and that we exaggerated it. While our relatives and close vicinity told us that there was no problem, we still went ahead and did research" (M3. p.12, ll. 482-485).

"They responded by saying male children would speak late anyway, they would be very active, they would be naughty" (M6, p.13, ll.500-503).

"My mother blamed me. She told me that I let the child watch too much TV and that was why he became like that, she told me I did not take care of my child" (M7, p.13, ll. 508-510). 


\subsubsection{Emotions Experienced While Raising Their Children}

Examination of mothers' statements about the emotions they experienced while raising their children who were diagnosed with ASD showed that six mothers (59\%) experienced intense "grief". A mother expressed her feelings as follows:

"Of course I'm sad; you know, thinking why he does not speak, why he is crying, why he does that to me; he cries because he cannot tell what he wants. And then, I sit down to cry while he is crying because I cannot understand him. I cry thinking why this child is like that" (M16, p.23, ll. 915-916).

Another mother expressed her feelings in the following manner: "I am very exhausted psychologically. It feels like I am better this year. But at first I was very distressed" (M1, p.19, ll.739-740). When asked why she felt better this year, she commented by saying, "I have gained some experience and got used to it. At first I was in shock and I did not know what to do and I did not know anything. Now at least I have some knowledge and learned what I should do" (MI, p.19, ll.741-743).

There were also mothers (12\%) who stated they experienced "fear and anxiety" and mothers (30\%) who felt "despair". Some of the outstanding examples for these issues were expressed as follows:

"There is fear. When we go to a doctor we experience stress, thinking that we will hear something to be afraid of again. We think we will definitely learn there is a problem. We are going to doctors every six months since he was two years old" (M3, p.20, ll. 806-808).

"We are scared and anxious since he is a child living in his own world, who only looks at the ceiling; he is a child lying between the sofas and never communicating with us" (M1, p.19, ll. 764-765).

"He used to cry when he could not communicate something to me. I thought he would never talk; I experienced despair and helplessness" (M16, p.23, ll. 916-917).

"When we first started education, we could not observe any progress, and we were so desperate thinking he could not learn anything, he could never speak" (M15, p.23, ll.901-903).

\subsubsection{Feelings That Have Changed}

Mothers were asked whether their emotions had changed since the day their children were diagnosed with ASD. Nine $(53 \%)$ of the mothers stated that their emotions underwent change while eight mothers reported no change and experienced these feelings with the same intensity. Mothers who stated that their feelings changed positively in the special education process for their children also added that if they had the chance to return to the moment of diagnosis; they would feel less grief, have lower anxiety and would act with more awareness. A mother's opinion on this subject is as follows:

"Of course, there would be differences in our reactions, we would at least know how to react. In the past, we did not know what we were going to do, for instance the child is uncomfortable when we go to a crowded place, he is uncomfortable when we go to market and now we either do not go to market or stay there a short time even if we do. We are adjusting everything according to our child; not according to us"(M17, p.27, ll. 1074-1079).

Another mother responded by saying; "I would not feel the same things, I am more experienced now" (M14, s.27, $l l$. 1056-1957). When asked why she would not feel those past emotions and how she got experience; she stated that; "I learned a lot in this process, at first I did not know anything. For example, I did not know that such special education opportunities existed, (if I did) I would have my child attend early education earlier"' M14, p.27, ll. 1057-1058).

\subsection{Changes in Family Life}

The theme of changes in family life was examined under two headings: "changes in the lives and habits of mothers" and "changes in marital life".

\subsubsection{Changes in Mothers' Lives and Habits}

Mothers stated that there were some changes in their lives and habits after their children were diagnosed with ASD. These changes included doing research, collecting information and reading about autism as expressed by 11 participating mothers $(65 \%)$ who stated asking themselves what they could do at this stage after the diagnosis. Two of the mothers $(12 \%)$ stated that they observed their children constantly and that their time had passed by examining their children. Four of the mothers (24\%) stated that they had their children attend special education. Some prominent mother views on these issues are:

"Thinking what I should do at this point, I started doing research. I did a lot of research, as much as I could" (MI, p.3, ll. 115-116). 
"I did search the Internet, read articles on the subject, read books about what others went through and their experiences" (M2, p.8, ll. 298-300).

"I knew I had to do something, so in order not to be late I applied to receive special education (for my child)" (M8, p.13, ll. 517-520).

\subsubsection{Changes in Marital Life}

In response to question that inquired about the changes in their marital lives after their children were diagnosed with ASD, all mother except one stated that their lives changed either positively or negatively. One of the mothers (12\%) who commented that that there was a negative change in her marital life stated:

"At first we started blaming each other. He argued that it happened because of me, I told him it was his fault. We came on the brink of divorce " $(M 1, p .15$, ll. 586-588).

One of the mothers (\% 24) who commented that that there was a positive change in her marital life stated that:

"I can say that the two of us, I and my husband, felt more attached and connected to each other. We started not making any decisions without notifying one another since our son have become our focal point" (M17, p.19, ll. 731-734).

Ten mothers (59\%) who participated in the study indicated that their marital life revolved around their children with ASD and that their lives were child-centered. Some mother opinions in this regard are as follows:

"Our marriage revolves around our child, he has our first interest, and our life now is entirely child-centered" (M7, p.17, ll. 674-675).

"We have planned our daily activities around the child and we started to adjust everything according to him" (M3, p.16,

ll. 613-614).

\subsection{Unsettling Situations for Mothers}

During the interviews, mothers were asked about the situations that upset and unsettled them in their experience of having a child with ASD. Six (35\%) of the participating mothers remarked that they did not experience a very unsettling situation.

However, five $(29 \%)$ of the mothers stated that events which were highly distressing for them resulted from their children's inability to express themselves in addition to experiences related to negative reactions from others and experiences caused by misinformation about their children. Some mothers expressed the following in regards to their grief caused by their children's inability to express themselves:

"The most saddening thing is that he can't express that he is hungry; he eats if I feed him, otherwise he goes hungry and does not ask for food" (M3. p. 32. ll.1256-1258).

"He does not respond, he does not react to anything. I call him by name; he does not look at me. His unresponsiveness is what makes me very sad" (M2 p.32, ll.1233-1236).

The other unsettling issue for the mothers was the negative reactions of otters. Four of the mothers (24\%) stated that other individuals blamed them and that really distressed them.

"Other people have worn me a lot; they stare when we go to the park (because) my child cannot talk. They constantly ask why he is unable to talk; they have really worn me down" (M6, p.33, l. 1278- l.1280).

"It was my mother who distressed me the most. My mother constantly criticized my behaviors towards my child, saying that I was doing it "wrong" and it was all "because of me" (M7, p.33, ll. 1286-1288).

Also, two of the mothers $(12 \%)$ stated that they were unsettled because they were given misinformation about their children.

"The only thing that upset me was being misinformed by a doctor, that really made me sad. (At first) she was diagnosed with something else and I was told by this doctor that her recovery would be a miracle" (M12, p.34. ll. 1316-1320).

\subsection{Thoughts for the Future}

Mothers were asked in the interviews about their thoughts in regards to their children's futures. Mothers 'responses about their future expectations were grouped under three headings: concerns about school life (35\%), uncertainty about the future (30\%) and unrealistic expectations about their children's future (24\%).

The interviews conducted with mothers pointed out to concerns about their children's future school experiences. It was determined that their concerns regarding this were related to adaptation to school and whether they would succeed when they started primary school. Some of the significant statements made by mothers are as follows:

"Now everything is fine but in the future it is the primary school that scares me the most. I am concerned thinking if he 
will sit in his seat, if he will listen to the teacher" (M1, p.35. ll. 1374-1375).

"I contemplate about the primary school, now he started to talk a little but I am worried about whether he can adapt to school and his friends, follow the courses, succeed... Will he be excluded by his teachers, by his friends? I am mostly worried about those" (M7, p.37 ll. 1447-1452).

In addition, some highlights from mothers' statements regarding the uncertainty about the future are as follows:

"I am very worried about what will happen in the future, how things will go, these are always in my mind, but I cannot foresee anything. We will just see when my daughter grows up" (M12, p. 38. ll. 1483-1484).

"I do not know what awaits me about my child's future and what will happen in the future. I will go with the flow" (M14, p. 38, ll. 1489-1490).

During the interviews conducted with mothers, it was observed that some mothers had unrealistic expectations about the future of their children. Some significant statements in regards to this issue are provided below:

"We're always positive. We have hope that he will be a surgeon or a doctor. He will be a successful person. We think positively" (M3, p.36, ll. 1411-1413).

"I do not think there will be any obstacle whatsoever about his future" (M15, p. 38, ll. 1494-1495).

"I want him to be a gendarmerie in the future, my expectation is that he will make my dream come true, that's all I want" (M17, p.39, ll. 1513-1514).

\subsection{Source of Emotional Support}

During the interviews, the participating mothers were asked with whom they shared their feelings the most. Ten mothers (53\%) stated that they received emotional support by sharing their feelings with their close relatives (both with their own mothers, fathers, siblings and their husbands' mothers, fathers, and siblings); five mothers $(30 \%)$ with their husbands, one mother $(6 \%)$ with families who had children diagnosed with ASD, one mother $(6 \%)$ with her friends and one mother $(6 \%)$ received emotional support from teachers. One of the mothers who reported receiving emotional support from close relatives stated her thoughts as follows:

"(I share my emotions) with our closest relatives, that is, I shared my feelings with his aunt, my mother, my elder brother. But, on the other hand, I kept thinking whether they are telling me the truth or just trying to calm me down. Even if the person was someone who was one of the people closest to me; I was not sure if they shared their actual thoughts or they wanted to soothe me when they told me this child had no problems and we were exaggerating" (M3, p.42, ll. 1592-1596).

Some of the mothers stating that they share their emotions with their husbands the most commented as follows:

"I shared my emotions with my husband the most. My husband is really a very concerned father; he has been very helpful to me in terms emotional support” (M12, p.44, ll. 1724-1725).

"My husband is very supportive emotionally. Therefore, I did not have much worry and despair" (M15, p.45, ll. 17501751).

In addition, the mother who mentioned sharing her feelings with other families who had children diagnosed with ASD stated that:

"I have communicated a lot with other families who have children like my child because they understand me the best" (M11, p.44, ll. 1726-1717).

Another mother stated that she shared her feelings with her friends:

"I talked with my friends the most. My friends did not spare me any material or moral support" (M17, p.45, ll.1767-1768).

Finally, a mother who stated sharing her feelings with the teachers expressed her opinion about the issue as follows:

"I talked with teachers and shared them my emotions with them. I had a lot of communication with teachers who have information in the field of autism" (M1, p.40, ll. 1546-1547). When asked why she was communicating with teachers, the mother explained the following; "I just wanted to communicate with those who knew what they were talking about, because others were not helpful" (M1, p.40, ll. 1548-1549).

\section{Discussion}

This study investigated the experiences of Turkish mothers whose children were diagnosed with ASD in terms of the emotions they felt and the challenges they encountered before and after the diagnosis. According to findings obtained from the interviews conducted with participating mothers of children with ASD ( $\mathrm{n}=17)$, mothers thought that their 
children had problems due to inadequate communication skills $(41 \%)$, limitations in social interaction (41\%) and problem behaviors $(6 \%)$. In particular, mothers stated that their children's inability to talk, establish eye contact, or opting to remain on their own were effective in their initial awareness of the social and communicative limitations their children with ASD had. Similar to the findings of this study, $66 \%$ of the families previously reported by Selimoğlu et al., (2014) had initially observed communication and social interaction deficiencies in their children later diagnosed with ASD. This finding is compatible with ASD diagnostic criteria in Diagnostic and Statistical Manual of Mental Disorders -V (DSM-V) such as persistent incompetence and limited, repetitive behavior in social communication and interaction (American Psychiatric Association, 2013). In addition, mothers of children with ASD reported that they were first warned about the developmental disorder in their children by the senior members of their families (23\%) or relatives $(23 \%)$ and doctors $(76 \%)$. Mothers noted that their observations had already suggested that something was wrong with their children or they had some type of incompetence/disorder and their thoughts were consolidated by their elders' or doctors' views. Similarly, in their study, Selimoğlu et al., (2014) stated that $70 \%$ of their mothers became aware of differences in their children at 1-2.5 years of age and 6\% of them realized that in 4 years of age. Also, all of the mothers in this study stated that ASD diagnosis was provided by doctors at the hospital.

Consistent with the findings of this study, relevant literature (Howlin \& Moore 1997; Biçak, 2009) states that diagnosis is made by doctors by observing the behavior of the child, collecting information from the family and taking the diagnostic criteria of the doctors into consideration. Furthermore, $88 \%$ of the mothers in this study reported that their children were diagnosed with ASD at the age range of 2-3 years and $12 \%$ reported that their children were diagnosed with ASD at the age range of 1-2 years. Similarly, Howlin \& Moore (1997) found in their study that ASD symptoms in children were first recognized by mothers around the age of 18 months, and that medical diagnosis was provided when children were around 2 years of age during the preschool period.

Another finding of this study is related to emotional reactions of mothers subsequent to their children's ASD diagnosis. Participant mothers reported sadness and constant bouts of crying (47\%) immediately after the diagnosis, refusal and denial of the diagnosis $(41 \%)$ and fear along with anxiety $(6 \%)$. These findings related to these intense and unchanging emotions experienced by mothers in the post-diagnosis period are parallel to the parental reactions identified in previous studies (Bıçak, 2009; Cavkaytar et al., 2008; Diken, 2006; Essex, 2002; Ferguson, 2002; Gargiulo \& Graves, 1991; Huang et al., 2010; McCabe, 2008; Selimoğlu et al., 2014, 2014; Vardarc1, 2011). Similarly, the information obtained in this study from the interviews conducted with mothers showed that fathers refused to accept ASD diagnosis (59\%) and they experience grief (35\%). Also, according to findings obtained from interviews, other family members (paternal and maternal grandmothers etc.) also did not accept the diagnosis (47\%), experienced sadness (24\%) and blamed the matter and father as parents $(30 \%)$.

Another finding from this research is related to the theme changes in family life. Mothers noted that changes in their family life after their children were diagnosed with ASD included by spending most of their time conducting research and collecting information (29\%) on ASD and examining and observing their children (12\%). In addition, while some mothers $(24 \%)$ stated that their marital lives were positively affected and they were more attached to their spouses, some mothers (12\%) stated that their marriages were negatively affected in this process. Furthermore, a large proportion of the mothers (59\%) declared that their children who were diagnosed with ASD were at the center of their marital life. Consistent with relevant literature (Ciğerli et al., 2014; Lai \& Mackenzie, 2002; McCabe, 2008; Vardarc1, 2011) and based on these findings, it can be argued that family life in general and marital relationships of some parents in particular may be negatively affected as a result of having a child diagnosed with ASD since the child will be at the center of the family life, mothers will tend to spend a large portion of their time on doing research on ASD and experts, fathers may refuse to accept the diagnosis and there may be imbalances in sharing responsibilities.

Another finding from this study is related to negative experiences. Some of the mothers who participated in the study (29\%) reported experiencing very distressing events or situations, most significant of which were found to be inability of their children to express themselves, negative, hurtful approaches of others and their offending reactions and being misinformed about their children. In particular; similar to the findings of previous studies (Desai et al., 2012; McCabe, 2008), some mothers stated that they felt distressed an unsettled when they were misinformed about ASD and their children by the doctors who diagnosed their children and that they experienced negative feelings such as helplessness. Consistent with previous findings (Bıçak, 2009; Bilgin \& Küçük, 2010; Selimoğlu et al., 2014; Üstüner-Top, 2009), the mothers who participated in this study were disturbed and unsettled when they were questioned by others about their children's inability to talk and when their children's behaviors were scrutinized.

Another finding from this research is related to the theme expectations for the future. The mothers were found to have negative (35\%) and unrealistic expectations (24\%) as well as being uncertain (30\%) about the future. Similar to the findings of previous studies (Essex, 2002; McCabe, 2008), it was found that negative thoughts and concerns of mothers about the future were more related to education and school experiences of their children, such as adapting to elementary 
school after preschool inclusion classes, overcoming difficulties they would encounter and achieving success at school. Moreover, it was determined that based on the inability to accept the diagnosis, some mothers had unrealistic goals and expectations that require university attendance or very professional education for their children such as educating them as doctors or man-at-arms. In addition, some mothers were observed to have concerns or anxiety stemming from uncertainty and not knowing what the future holds for them and their children.

The last finding from this study is related to the theme source of emotional support. It was found that the mothers who participated in the study needed emotional and social support and they attempted to meet these needs with the people in their surroundings (their parents and siblings, parents and siblings of their spouses (53\%), their spouses (30\%), families of children with ASD (6\%), their own friends (6\%) and teachers (6\%). It was found that mothers tried to find social and emotional support primarily from inner circles or first-degree relatives (their parents, siblings and spouses). Similar to the findings of previous studies conducted with mothers of children with disabilities in other societies (Lai \& Mackenzie, 2002; Ong et al., 2005; Desai et al., 2012; McCabe, 2008), this study identified that Turkish mothers of children with ASD also were in search for both emotional and social support in the face of difficulties they have experienced.

The implications of the study and the conclusions and suggestions based on these findings are provided below:

1. Based on the findings of this research, it can be argued that many mothers are aware of ASD related communication skills limitations, social interaction limitations and problem behaviors but they do not have sufficient information about ASD. It is noted in relevant literature (Zwaigenbaum et al., 2009) that good observations by mothers around the age of one increase the rate of correct ASD diagnosis by doctors at two years of age. This study once again demonstrates the necessity of including family and taking mothers' observations into account during both medical and educational diagnosis process. Introduction of intensive early special education services with early diagnosis of children with ASD may increase the participation of these children in social life. For this reason, it is necessary to provide mothers with informational documents and materials to raise awareness in post natal checks in health institutions and broadcast and publish promotional publications about ASD in media (TV, radio, Internet etc.) may be effective and beneficial to have mothers recognize problems related to in their children and to take support from early special education services.

2. The study found that, similar to the feelings of other family members, mothers experienced intense grief, anxiety, fear, refusal and denial after their children were diagnosed with ASD by their doctors. These intense emotions may delay the use of early special education services despite the diagnosis. For this reason, it is necessary to provide psychological support services within the scope of early special education services to families, especially to mothers. Psychological counseling services provided to parents can be planned and implemented within the framework of early special education services.

3. Research findings demonstrate that feelings experienced by mothers such as fear, anxiety and hopelessness after their children were diagnosed with ASD changed positively within the special education process they received and they felt less sorrow and anxiety and became more aware of ASD as they gained experience. These findings reveal the necessity of informative and introductory education services for mothers after ASD diagnosis along with special education services provided for their children. Thus, the mothers will be emotionally prepared earlier, be able to accept their children more readily, learn the characteristics of ASD and behave with higher awareness towards their children with ASD.

4. According to research findings, it was determined that many families have their children with ASD at the center of their lives and that a large part of mothers' time was devoted to doing research and collecting information about ASD. Offering mothers information-based counseling services (face-to-face information sessions, ASD intro meetings, online information, social media services, etc.) in the context of early education services to provide them with information with the right resources and experts will contribute to mothers' spending their time with their spouses and other children. Thus, marital relationships of families of children with ASD will be supported as well. In addition, accurate information provided to families and mothers will ensure that appropriate and realistic goals can be established for children with ASD and thus it will contribute to effectiveness and efficiency of special education services.

5. Mothers stated that they received emotional support from their own family members and their spouses the most. However, many mothers of children with ASD experience intense emotional problems (grief, anxiety, stress, etc.) and the support of people in their inner circles may be insufficient in such cases. Therefore, emotional and psychological support provided by specialists may be needed. Social and emotional support services can be provided by experts in the field (consultants, psychologists, etc.) by extending the family training and psychological counseling services within the scope of early special education services. 
On a final note, this study investigated the experiences of Turkish mothers whose children were diagnosed with ASD in terms of the emotions they felt and the challenges they encountered. Findings obtained from the study and the implications derive from the results can contribute to the planning and implementation of early special education services for mothers. Future studies may explore the effects of early special education services provided for mothers of children with ASD and their families on the educational development of their children.

\section{References}

American Psychiatric Association (2013). Diagnostic and statistical manual of mental disorders (5th ed.). Arlington, VA: American Psychiatric Association. https://doi.org/10.1176/appi.books.9780890425596

Bıçak, N. (2009). Identfying the experiences of mothers with children with autism. Master's Thesis, Abant İzzet Baysal Üniversitesi, Bolu

Bilgin, H., \& Küçük, L. (2010). Raising an autistic child: Perspectives from Turkish Mothers. Journal of Child and Adolescent Psychiatric Nursing, 23, 92-98. https://doi.org/10.1111/j.1744-6171.2010.00228.x

Bronfenbrenner, U. (1979). The ecology of human development, Harvard University Press, Cambridge, MA, USA.

Cavkaytar, A., Batu, S., \& Cetin, O. B. (2008). Perspectives of Turkish mothers on having a child with developmental disabilities. International Journal of Special Education, 23(2), 101-109.

Ciğerli, O., Topsever, P., Filiz-Alvur, T. M., \& Görpelioğlu, S. (2014). Parental experiences and coping skills of the parents of disabled children living in Kocaeli, Turkey. Balkan Journal of Health Science, 2(2), 48-56.

Davison, G. C., \& Neale, J. M. (2004). Abnormal Psychology, Dağ, İ. (translator/editor). Türk Psikologlar Derneği Yayınları.

Desai, M. U., Divan, G., Wertz, F. J., \& Patel, V. (2012). The discovery of autism: Indian parents' experiences of caring for their child with an autism spectrum disorder. Transcultural Psychiatry, 49, 613-637. https://doi.org/10.1177/1363461512447139

Diken, I. H. (2006). Turkish mothers' interpretation of the disability of their children with mental retardation. International Journal of Special Education, 21(2), 8-17.

Essex, E. (2002). Mothers and fathers of adults with mental retardation: Feelings of intergenerational closeness. Family Relations, 51, 156-166. https://doi.org/10.1111/j.1741-3729.2002.00156.x

Ferguson, P. M. (2002). A place in the family. A historical interpretation of research on parental reactions to having child with a disability. Journal of Special Education, 36, 124-136. https://doi.org/10.1177/00224669020360030201

Gargiulo, R. M., \& Graves, S. B. (1991). Parental feelings: The forgotten component when working with parents of handicapped preschool children. Childhood Education, 67(3), 176-178.

https://doi.org/10.1080/00094056.1991.10521603

Güleç-Aslan, Y., Cihan, H., \& Altın, D. (2014). Living with a child with autism spectrum disorders: Experiences of mothers. Elektronik Sosyal Bilimler Dergisi. 13(50), 96-111. https://doi.org/ 10.17755/esosder.41128

Halladay, A. K., Bishop, S., Constantino, J. N., Daniels, A. M., Koenig, K., Palmer, K., ... \& Taylor, J. L. (2015). Sex and gender differences in autism spectrum disorder: summarizing evidence gaps and identifying emerging areas of priority. Molecular autism, 6(1), 36. https://doi.org/10.1186/s13229-015-0019-y

Hallahan, D. P., \& Kaufmann, J. M. (2009). Exceptional Learners: Introduction to special education. Boston: Allyn \& Bacon.

Howlin, P., \& Moore, A. (1997). Diagnosis in autism: a survey of over 1200 patients in the UK. Autism, 1(2), 135-162. https://doi.org/10.1177/1362361397012003

Huang, Y. P., Kellett, U. M., \& St John, W. (2010). Cerebral palsy: experiences of mothers after learning their child's diagnosis. Journal of Advanced Nursing, 66(6), 1213-21. https://doi.org/10.1111/j.1365-2648.2010.05270.x

Kermanshahi, S. M., Vanaki, Z., Ahmedi, F., Kazemnejad, A., \& Azadfalah, P. (2008). Children with learning disabilities: A phenomenological study of the lived experiences of Iranian mothers. International Journal of Qualitative Studies on Health and Well-being, 3(1), 18-26. https://doi.org/10.1080/17482620701757284

Kerr, D., \& Mcintosh, J. B. (2000). Coping when a child has a disability: Exploring the impact of parent to parent support. Child Care Health and Development, 26(4), 309-322. https://doi.org/10.1046/j.1365-2214.2000.00149.x

Lai, W. L., \& Mackenzie, A. N. (2002). Coping with a child with Down syndrome: The experiences of mothers in Hong Kong. Qualitative Health Research, 12(2), 223-237. https://doi.org/10.1177/104973202129119856 
McCabe, H. (2008). Autism and family in the People's Republic of China: Learning from Parents' Perspectives. Research and Practice for Persons with Severe Disabilities. 31(1-2), 37-47. https://doi.org/10.2511/rpsd.33.1-2.37

Ong, L., Chandran V., \& Peng, R. (2005). Stress experienced by mothers of Malaysian children with mental retardation. Journal of Intellectual Disability Research, 49(9), 657-671.

Roach, M. A., \& Orsmand, G. I. (1999). Mothers and fathers of children with Down syndrome: Parental stress and involvement in child care. American Journal of Mental Retardation, 104(5), 422-436. https://doi.org/10.1352/0895-8017(1999)104<0422:MAFOCW >2.0.CO;2

Sameroff, A. J., \& Fiese, B. H. (2000). Transactional regulation: The developmental ecology of early intervention, handbook of early childhood intervention, J. P. Shonkoff \& S. J. Meisels (Eds.), Cambridge University Press, New York

Sari, H. Y., Baser, G., \& Turan, J. M. (2006). Experiences of mothers of children with Down syndrome. Paediatric Nursing, 18(4), 29-32. https://doi.org/10.7748/paed2006.05.18.4.29.c1024

Selimoğlu, Ö., Özdemir, S., Töret, G., \& Özkubat, U. (2014). Examining the views of parents with autistic children about their experiences in the autism process and after the diagnosis. International Journal of Early Childhood Special Education, 15(2), 129-161. https://doi.org/ 10.20489/intjecse.107930

Üstüner-Top, F. (2009). Assessing the problems and mental conditions of families with autistic children: Qualitative Research. Çocuk Dergisi, 9(1), 34-42

Vardarc1, G. (2011). Influence of the family education program provided for families with autistic children on family communication skills, family problem-solving skills and perceptions of their autistic children. Yüksek lisans tezi/Master's Thesis, Dokuz Eylül Üniversitesi, İzmir.

Wehman, T. (1998). Family-centered early intervention services: Factors contributing to increased parent involvement and participation. Focus on Autism and Other Developmental Disabilities, 13(2), 80-87. https://doi.org/10.1177/108835769801300203

Yıldırım, A., \& Şimşek, H. (2008). Qualitative research methods in social sciences, Seçkin Yayıncılık, 7. Baskı. Ankara

Zwaigenbaum, L., Bryson, S., Lord, C., Rogers, S., Carter, A., Carver, L., ... \& Fein, D. (2009). Clinical assessment and management of toddlers with suspected autism spectrum disorder: insights from studies of high-risk infants. Pediatrics, 123(5), 1383-1391. https://doi.org/10.1542/peds.2008-1606

\section{Copyrights}

Copyright for this article is retained by the author(s), with first publication rights granted to the journal.

This is an open-access article distributed under the terms and conditions of the Creative Commons Attribution license which permits unrestricted use, distribution, and reproduction in any medium, provided the original work is properly cited. 